Article

\title{
Effects of DMT and TMPTMA on Working Life of Acrylic Polymer Concrete Exposed to Low Curing Temperatures
}

\author{
Kyu-Seok Yeon ${ }^{1}$, Jin-Yun Cha ${ }^{1}$ and Jung Heum Yeon ${ }^{2, *}$ \\ ${ }^{1}$ Department of Regional Infrastructure Engineering, Kangwon National University, \\ Chuncheon 200-701, Korea; E-Mails: ksyeon@kangwon.ac.kr (K.-S.Y.); \\ cdcome@kangwon.ac.kr (J.-Y.C) \\ ${ }^{2}$ Department of Civil and Environmental Engineering, Gachon University, Seongnam 461-701, Korea \\ * Author to whom correspondence should be addressed; E-Mail: jyeon@ @achon.ac.kr; \\ Tel.: +82-31-750-5498; Fax: +82-31-750-5344.
}

Received: 19 May 2015 / Accepted: 20 August 2015 / Published: 26 August 2015

\begin{abstract}
Ensuring an appropriate casting time window is of great importance for achieving desired quality and performance of aging materials. In this paper, the effects of promoter and cross-linking agent on the working life-the period a mixture stays in a workable condition-of low-temperature-cured acrylic polymer concrete (PC) are investigated in order to develop mixture proportions that can be effectively applied in cold weather conditions. The experimental variables included in this study are: (1) curing temperatures $(-20,-10$ and $0{ }^{\circ} \mathrm{C}$ ); (2) $N, N$-dimethyl-p-toluidine (DMT) contents $(0.5,1.0,1.5$ and $2.0 \mathrm{phr}$ (parts per hundred parts of resin)); and (3) trimethylolpropane trimethacrylate (TMPTMA) contents $(0,2.5$ and $5 \mathrm{phr})$. Results indicated a strong relevance between binder's setting time and PC's working life. Additionally, it was observed that the working life of acrylic PC was substantially shortened as the curing temperature and contents of DMT and TMPTMA increased. Results of a two-way analysis of variance (ANOVA) revealed that TMPTMA had a greater impact on the working life than DMT. Finally, this study developed an equation that can be used to estimate PC working life, based on the binder's setting time. The findings of this study will be used as valuable information for cold weather applications of acrylic PC.
\end{abstract}

Keywords: acrylic polymer concrete; working life; setting time; curing temperature; promoter; cross-linking agent 


\section{Introduction}

Polymer concrete (PC) is a type of construction and repair materials composed of organic polymer, inorganic aggregate, and filler. PC is generally used in precast applications, including manholes, pipes, and chemical-resistance vessels, due to its favorable material properties, such as high mechanical strength, strong chemical resistance, as well as its short time to obtain satisfactory serviceability [1-3]. In addition, PC is widely accepted for rapid repair of pavement and bridge decks, as well as in corrosion protections of a variety of in-service infrastructures exposed to aggressive environments, in order to extend their lifespans due to its excellent durability, strong adhesiveness, and rapid hardening characteristics [1,4]. As binders for PC, epoxy resin, unsaturated polyester (UP) resin, polymethyl methacrylate (PMMA) resin, vinylester resin, and furan resin are popularly used [2,5]. Among them, acrylic PC using PMMA resin as a binder is well known to have benefits in workability, low-temperature curing, and weather resistance. Especially, as PMMA resin has a low viscosity, a good workability can be readily obtained, compared with other PCs using epoxy resin and UP resin as binders.

One of the important parameters in applying PC is its working life-also referred to as "working time" or "gel time" [6] - the practical time limit beyond which a mixture is incapable of being molded and finished, thereby reaching an unworkable condition. In contrast to Portland cement concrete, typically exhibiting a final setting time of 6 to $7 \mathrm{~h}$ at room temperature [7], PC has a much smaller binder setting time, and in turn, a working life. Additionally, the working life of PC is quite sensitive to curing temperature and additive types and content. Accordingly, ensuring an adequate working life is important for achieving desired quality and performance of PC. If the working life is too short, it would result in improper compaction and surface finishing of the mixture, which will ultimately result in poor performance. On the contrary, if the working life is too long, it would lead to a delay in the construction and service process (e.g., delayed formwork removal and opening to traffic).

There have been few studies concerned with the working life of acrylic PC and the setting time of acrylic binder. Ohama et al. [8] evaluated the working life of acrylic PC comprised of $90 \mathrm{wt} \%$ methyl methacrylate (MMA), $5 \mathrm{wt} \%$ PMMA, and $5 \mathrm{wt} \%$ trimethylolpropane trimethacrylate (TMPTMA) binders with $N, N$-dimethylaniline (DMA) and $N, N$-dimethyl- $p$-toluidine (DMT) promoters, at curing temperatures of 10,20 , and $30{ }^{\circ} \mathrm{C}$. Their results have shown that (1) the effect of DMT was greater than DMA; and (2) benzoyl peroxide (BPO) initiator hardly affected the working life. Haddad et al. [9] reported the effects of curing temperatures $\left(-1,10,21\right.$ and $\left.38^{\circ} \mathrm{C}\right)$ and BPO:DMT ratios $(2: 1$ and 3:1) on the working life, compressive strength, and elastic modulus of acrylic PC composed of 95 wt \% MMA and 5 wt \% TMPTMA binders. Kobayashi et al. [10] investigated the setting time of acrylic binder composed of $90 \mathrm{wt} \%$ MMA, $5 \mathrm{wt} \%$ PMMA with varying contents of TMPTMA, from 5 to $20 \mathrm{wt} \%$. The BPO content was $2 \mathrm{wt} \%$ while the DMT content were 1, 2, 3 and $5 \mathrm{wt} \%$. The curing temperatures investigated were $0,-10$ and $-20^{\circ} \mathrm{C}$.

In this study, the effects of DMT promoter and TMTPMA cross-linking agent on the working life of acrylic PC cured at low temperatures are assessed based on laboratory testing in order to suggest optimum mixture proportions that can be effectively applied in cold weather conditions. Additionally, this study attempts to develop an easy-to-use prediction model for estimating the working life of acrylic PC based on the binder's setting time. The findings of this study will be used as valuable information for cold weather applications of acrylic PC, especially for rapid repair works during the winter season. 


\section{Experimental Program}

\subsection{Materials}

\subsubsection{Binder}

This study used an acrylic resin, which typically has good soundness, weather resistance, and transparency, as a binder; the acrylic resin was produced by dissolving a PMMA powder (LG MMA, Yeosu, Korea) in MMA monomer (LG MMA, Yeosu, Korea). The PMMA is a white microspherical powder soluble in MMA monomer that plays the role of thickening agent, controlling the viscosity of MMA monomer. As an initiator, BPO (Hansol Chemical, Seoul, Korea), which creates a polymer by forming new radicals when combined with a monomer, was used. In addition, this study employed DMT (SK Petrochemical, Ulsan, Korea) as a promoter, which is commonly used for polymerization of polyester, acryl, and epoxy resins. TMPTMA (Yuwon Intec Inc., Gunpo, Korea), a highly reactive tri-functional monomer promoting the hardening reactions by free radical polymerization, was used as a cross-linking agent. The cross-linking agent produces a network-structured high molecule polymer by cross-linking the space between molecules of a linear-structured polymer. The physical properties MMA, BPO, DMT, and TMPTMA are summarized in Table 1.

Table 1. Physical properties of various binder components.

\begin{tabular}{cccccc}
\hline Components & $\begin{array}{c}\text { Density } \\
\left(\mathbf{g} / \mathbf{c m}^{\mathbf{3}} \mathbf{\mathbf { 2 5 }}{ }^{\circ} \mathbf{C}\right)\end{array}$ & $\begin{array}{c}\text { Melting point } \\
\left({ }^{\circ} \mathbf{C}\right)\end{array}$ & $\begin{array}{c}\text { Viscosity } \\
(\mathbf{m P a} \cdot \mathbf{s})\end{array}$ & $\begin{array}{c}\text { Molecular weight } \\
(\mathbf{g} / \mathbf{m o l})\end{array}$ & Appearance \\
\hline MMA & 0.942 & -47.6 & $0.56\left(\right.$ at $\left.20^{\circ} \mathrm{C}\right)$ & 100.12 & Transparent \\
BPO & 1.334 & $104-105$ & - & 242.23 & $\begin{array}{c}\text { White } \\
\text { powder }\end{array}$ \\
DMT & 0.937 & -15 & $2.0\left(\right.$ at $\left.20^{\circ} \mathrm{C}\right)$ & 135.21 & $\begin{array}{c}\text { Liquid } \\
\text { TMPTMA }\end{array}$ \\
\hline
\end{tabular}

MMA, methyl methacrylate; BPO, benzoyl peroxide; DMT, $N, N$-dimethyl- $p$-toluidine; TMPTMA, trimethylolpropane trimethacrylate.

\subsubsection{Aggregate and Filler}

Washed silica sand (Kyungin Mineral Products, Gimpo, Korea) with a specific gravity of 2.64, a fineness modulus (i.e., an empirical figure indicating how coarse or fine the aggregate is) of 3.09, and a unit weight of $1648 \mathrm{~kg} / \mathrm{m}^{3}$ was used as fine aggregate. The moisture content of the fine aggregate was kept less than $0.1 \%$ as the moisture weakens the interfacial adhesion between the aggregate and the binder, consequently decreasing PC's strength. Figure 1 shows the gradation of the silica sand used, along with the upper and lower gradation limits provided in American Society for Testing and Materials (ASTM) C33 [11]. As a filler (Kyungin Mineral Products, Gimpo, Korea), ground calcium carbonate with a specific gravity of 0.75 , a moisture absorption of $0.2 \mathrm{cc} / \mathrm{gr}$, a moisture content of $\leqslant 0.3 \%$, a mean grain size of $13 \mu \mathrm{m}$, and a retained percentage on 325 mesh sieve of $0.03 \%$ was used. The chemical 
compositions of the calcium carbonate filler used were $53.7 \% \mathrm{CaO}, 0.25 \% \mathrm{Al}_{2} \mathrm{O}_{3}, 0.09 \% \mathrm{Fe}_{2} \mathrm{O}_{3}, 2.23 \%$ $\mathrm{SiO}_{2}, 0.66 \% \mathrm{MgO}$, and $42.4 \%$ loss on ignition.

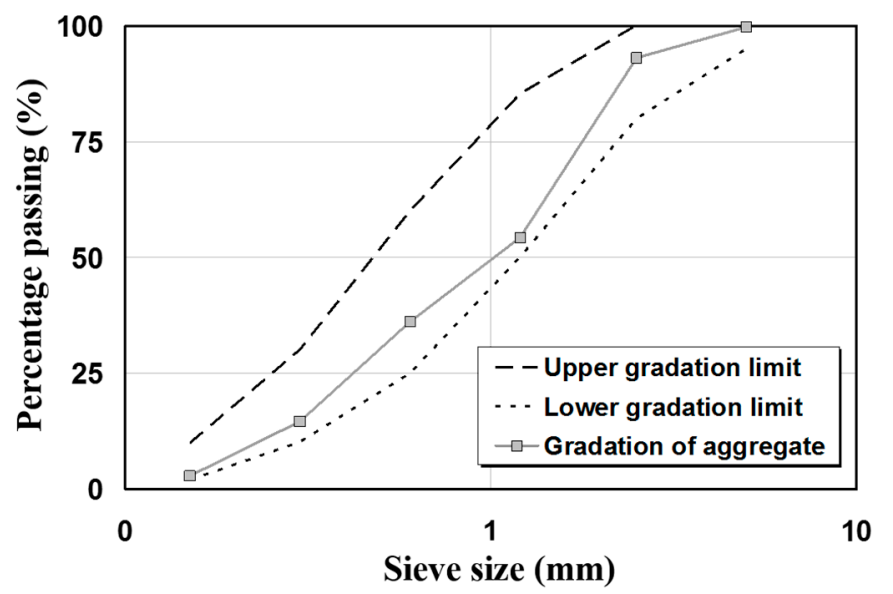

Figure 1. Gradation curve of silica sand.

\subsection{Binder Formation and Mixture Proportions}

\subsubsection{Optimum Binder Content}

A flow test, a method to measure the consistency of fresh concrete mixtures, was performed as per Japanese Industrial Standards (JIS) R 5201 [12] to determine the optimum binder content of acrylic PC. The mixtures used in this preliminary test had a fixed MMA:PMMA ratio and a binder:filler ratio of 80:20 and 1:1.5 by weight, respectively. Figure 2 shows the flow test results for different binder and TMPTMA contents. Based on the results, the optimum binder content was found to be 11-12 wt \%, with a corresponding flow value of $110-123 \mathrm{~mm}$ - severe segregation occurred due to a lack of binder when the flow value fell between 100 and $105 \mathrm{~mm}$ while bleeding was observed due to the excessive binder content when the flow value was greater than $130 \mathrm{~mm}$. In this study, an $11 \mathrm{wt} \%$ binder content yielding a flow value of about $110 \mathrm{~mm}$ was consistently used.

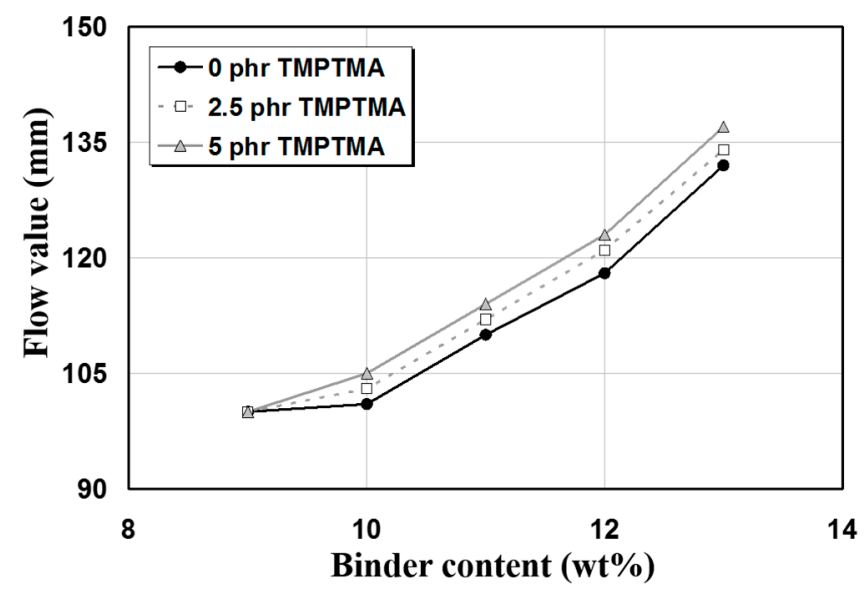

Figure 2. Effects of binder and TMPTMA contents on flow value. 


\subsubsection{Mixture Proportions}

The hardening (polymerization) of PC generally requires an initiator and a promoter as additives. It is well recognized that the initiator more affects the initiation of hardening reactions whereas the promoter more affects the setting time, and in turn, the working life of PC. Accordingly, this study used a fixed content of BPO initiator of $2 \mathrm{phr}$, while the content of DMT promoter varied between 0.5 and $2.0 \mathrm{phr}$. Table 2 shows the binder formulations and the mixture proportions of acrylic PC tested in this study.

Table 2. Binder formulations and mixture proportions of acrylic polymer concrete.

\begin{tabular}{|c|c|c|c|c|c|c|c|}
\hline \multirow{2}{*}{$\begin{array}{c}\text { Binder Content } \\
\text { (wt \%) }\end{array}$} & \multicolumn{5}{|c|}{ Binder Formulation (wt \%) } & \multirow{2}{*}{$\begin{array}{l}\text { Filler } \\
(\text { wt \%) }\end{array}$} & \multirow{2}{*}{$\begin{array}{c}\text { Aggregate } \\
\text { (wt \%) }\end{array}$} \\
\hline & MMA & PMMA & $\begin{array}{c}\text { BPO } \\
(\text { phr a) }\end{array}$ & $\begin{array}{l}\text { DMT } \\
\text { (phr) }\end{array}$ & $\begin{array}{l}\text { TMPTMA } \\
\quad(p h r)\end{array}$ & & \\
\hline 11 & 80 & 20 & 2 & $\begin{array}{l}0.5 \\
1.0 \\
1.5 \\
2.0\end{array}$ & $\begin{array}{l}0 \\
2.5 \\
5.0\end{array}$ & 16.5 & 72.5 \\
\hline
\end{tabular}

${ }^{\mathrm{a}}$, parts per hundred parts of resin.

\subsection{Methods}

\subsubsection{Setting Time of Polymeric Binder}

Polymeric binders undergo several hardening stages: (1) the point at which the binder is too viscous to be worked is referred to as "spinning"; (2) the point at which the gelation starts is termed "gelling"; and (3) the point at which the solidification occurs is termed "caking". In this study, the setting time of binder was defined as the time interval from the mixing to gelling [13]. The gelation time was approximated as the elapsed time from the start of mixing to which the binder no longer adheres to the end of a clean probe based on ASTM D2471 [14].

\subsubsection{Working Life of Polymer Concrete}

The most common test methods for measuring the working life of PC include the penetration method, pull-out resistance method, and finger-touching method. In this study, the finger-touching method provided in Reunion Internationale des Laboratoires et Experts des Materiaux, Systemes de Construction et Ouvrages (RILEM) TC-CPT 1995 (PC-4 Determining methods for working life of fresh polymer concrete and mortar), which estimates the working life based on the sense of touching the film on resin concrete using fingers [13], was adopted. 


\section{Results and Discussion}

\subsection{Setting Time of Polymeric Binder}

Figure 3a-c shows the effects of DMT and TMPTMA contents on the setting time of acrylic binder cured at $-20,-10$ and $0{ }^{\circ} \mathrm{C}$, respectively. The results indicate that the binder's setting time was significantly shortened as the DMT content increased from 0.5 to $2 \mathrm{phr}$. The DMT effect on the setting time reduction became greater as the curing temperature decreased from 0 to $-20{ }^{\circ} \mathrm{C}$, which demonstrates that the DMT works more effectively at lower curing temperatures.

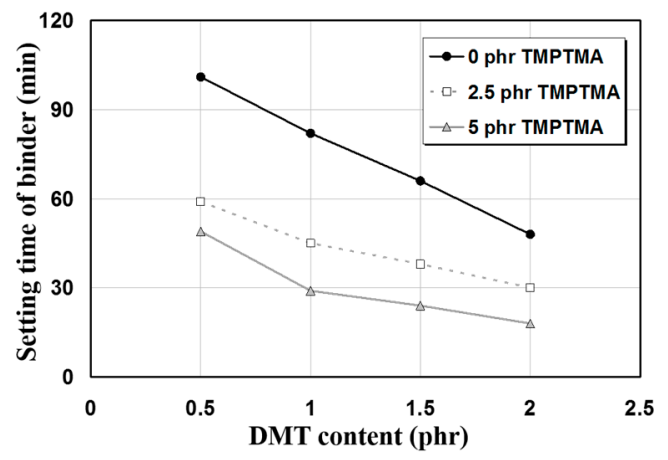

(a)

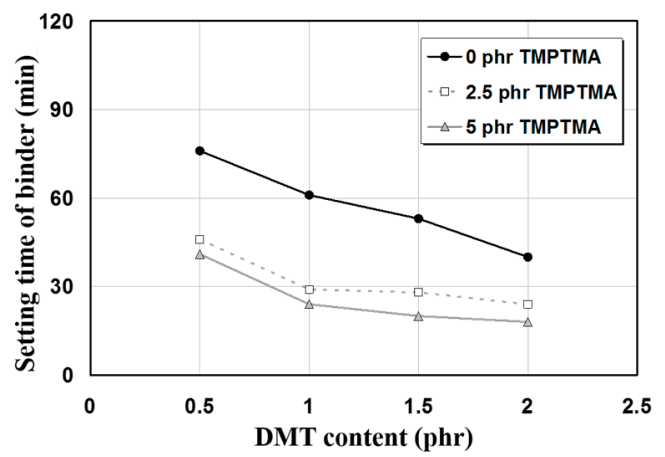

(b)

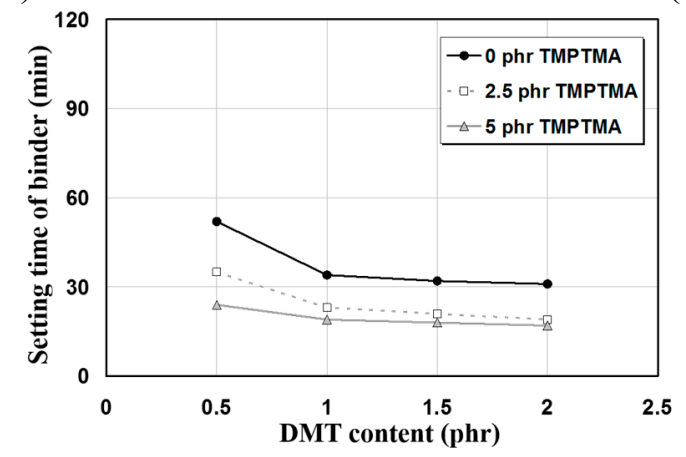

(c)

Figure 3. Effects of DMT and TMPTMA contents on the setting time of acrylic binder cured at different temperatures, (a) $-20{ }^{\circ} \mathrm{C}$; (b) $-10{ }^{\circ} \mathrm{C}$; and $(\mathbf{c}) 0^{\circ} \mathrm{C}$.

Also noted is that the setting time of binder was noticeably reduced as the curing temperature increased: $18-101 \mathrm{~min}$ at $-20^{\circ} \mathrm{C}, 18-76 \mathrm{~min}$ at $-10{ }^{\circ} \mathrm{C}$, and $17-52 \mathrm{~min}$ at $0{ }^{\circ} \mathrm{C}$. This behavior appears to be related with increased molecular motions as the thermal energy supply to the system increases at higher curing temperatures [15]. It is interesting to note that the setting time of binder was much less sensitive to curing temperature when the DMT content was 2 phr; especially, when the TMPTMA content was $5 \mathrm{phr}$, the setting time remained almost unchanged for all curing temperatures: 18 min at -20 and $-10{ }^{\circ} \mathrm{C}$ and $17 \mathrm{~min}$ at $0{ }^{\circ} \mathrm{C}$.

In addition, the results shown in Figure 3 indicate that the higher the TMPTMA content, the shorter the setting time. Especially, compared with the mixtures without TMPTMA, the mixtures with $2.5 \mathrm{phr}$ TMPTMA tended to have noticeably shorter setting times: $18-42 \mathrm{~min}$ shorter at $-20{ }^{\circ} \mathrm{C}, 16-30 \mathrm{~min}$ shorter at $-10^{\circ} \mathrm{C}$, and $11-17$ min shorter at $0{ }^{\circ} \mathrm{C}$. Note that the binder's setting time was more effectively reduced by addition of TMPTMA at lower curing temperatures. Only slight differences in setting 
time (i.e., 2-16 min) were observed between the $2.5 \mathrm{phr}$ TMPTMA mixtures and the $5 \mathrm{phr}$ TMPTMA mixtures. This finding implies that the excessive use of TMPTMA, more than $2.5 \mathrm{phr}$, could be an inefficient strategy for reducing the setting time of acrylic binder at low curing temperatures.

Compared with a previous study by Haddad et al. [9], which reported that the setting time of acrylic binder cured at $-1{ }^{\circ} \mathrm{C}$ was 47 min when $4 \%$ initiator and $2 \%$ promoter were used, and a previous study by Kobayashi et al. [10], which described that at least $2 \%$ promoter is required to secure the binder's setting time of $60 \mathrm{~min}$, the present study showed somewhat different results. This discrepancy appears to stem from the different PMMA contents selected in those studies.

From the results, it is concluded that the setting time of acrylic binder could be effectively controlled by additions of DMT and TMPTMA even at curing temperatures as low as $-20-0{ }^{\circ} \mathrm{C}$, which enables the production of acrylic PC even in cold weather conditions.

\subsection{Working Life of Polymer Concrete}

Figure 4 illustrates how the DMT and TMPTMA contents affect the working life of acrylic PC. Overall, the behavior trend was quite similar to that presented in Figure 3. First, it can be seen that the more the DMT content, the shorter the working life of acrylic PC. Note that the effect of DMT on the working life reduction of acrylic PC became more pronounced with decreased curing temperature; the working life reduction due to addition of $2 \mathrm{phr}$ DMT ranged from 29 to $53 \mathrm{~min}$ at $-20^{\circ} \mathrm{C}, 21$ to $51 \mathrm{~min}$ at $-10{ }^{\circ} \mathrm{C}$, and 16 to $47 \mathrm{~min}$ at $0{ }^{\circ} \mathrm{C}$.

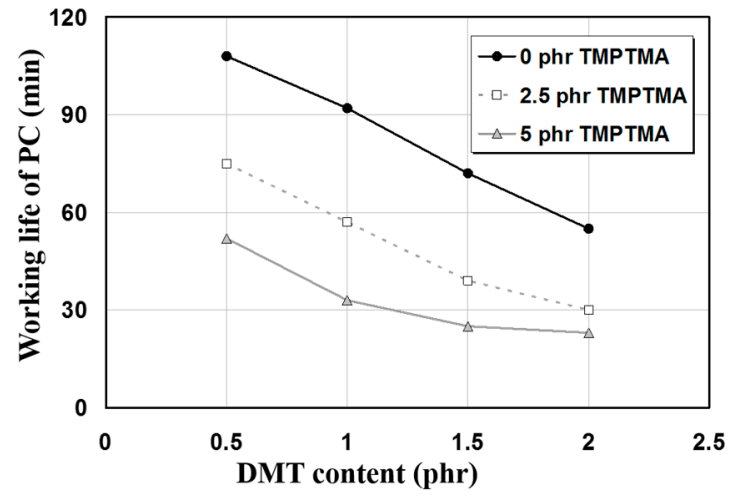

(a)

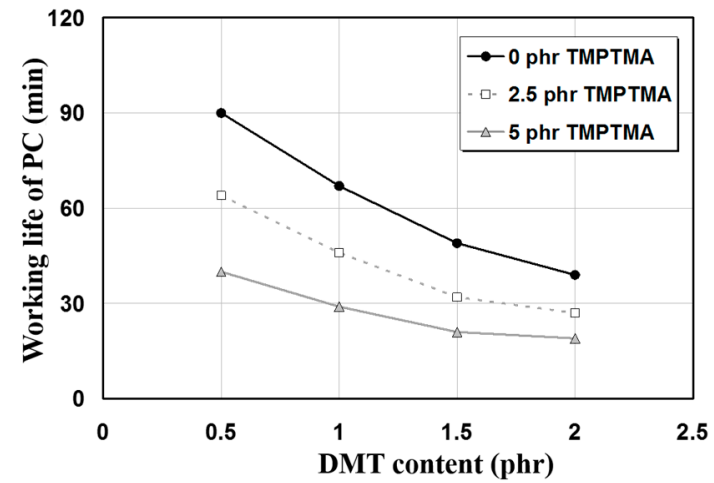

(b)

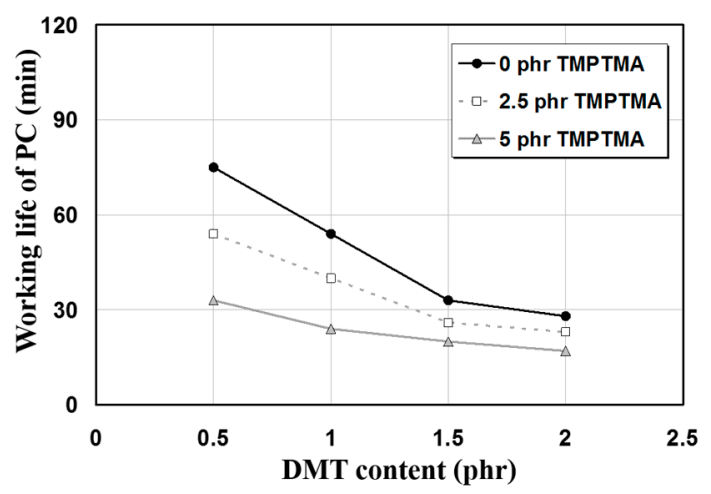

(c)

Figure 4. Effects of DMT and TMPTMA contents on the working life of acrylic polymer concrete cured at different temperatures. (a) $-20^{\circ} \mathrm{C} ;(\mathbf{b})-10{ }^{\circ} \mathrm{C}$; and $(\mathbf{c}) 0{ }^{\circ} \mathrm{C}$. 
Furthermore, the results clearly show that the curing temperature had a remarkable effect on the working life of acrylic PC, as expected. As the curing temperature increased from -20 to $0{ }^{\circ} \mathrm{C}$, the maximum and minimum working life tended to decrease: 108 and $23 \mathrm{~min}$ at $-20{ }^{\circ} \mathrm{C}, 90$ and $19 \mathrm{~min}$ at $-10{ }^{\circ} \mathrm{C}$, and 75 and $17 \mathrm{~min}$ at $0{ }^{\circ} \mathrm{C}$, respectively. Similar to the test results observed in Figure 3 , it is interesting to note that the minimum working life was nearly consistent, regardless of the curing temperature (i.e., 17-23 $\mathrm{min}$ ).

Additionally, Figure 4 indicates that the use of TMPTMA markedly reduced the working life of acrylic PC. Note that the effect of TMPTMA on the working life reduction became greater as the curing temperature decreased. Compared with the working life of acrylic PC without TMPTMA, the acrylic PC with $5 \mathrm{phr}$ TMPTMA was $11-42$ min shorter at $0{ }^{\circ} \mathrm{C}, 20-50 \mathrm{~min}$ shorter at $-10{ }^{\circ} \mathrm{C}$, and 32-59 min shorter at $-20{ }^{\circ} \mathrm{C}$. However, the effectiveness of TMPTMA tended to decrease with an increase in TMPTMA content, with only small reductions in working life between the $2.5 \mathrm{phr}$ mixtures and the $5 \mathrm{phr}$ mixtures, irrespective of the curing temperature. This finding suggests that the dosage of TMPTMA additive needs to be regulated to $2.5 \mathrm{phr}$ for its efficient use.

Figure 5 presents the reduction ratios of working life with respect to the mixture with a longest working life (i.e., the mixture cured at $-20{ }^{\circ} \mathrm{C}$ with $0.5 \mathrm{phr}$ DMT and $0 \mathrm{phr}$ TMPTMA). The analysis results indicate that the reduction ratio became greater as the DMT and TMPTMA contents increased. However, the reduction ratio tended to decrease as the curing temperature decreased, indicating that the effectiveness of DMT and TMPTMA is reduced as the curing temperature decreases.

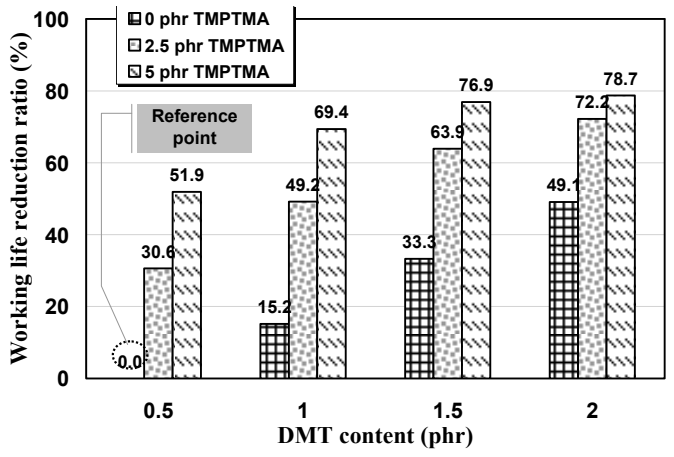

(a)

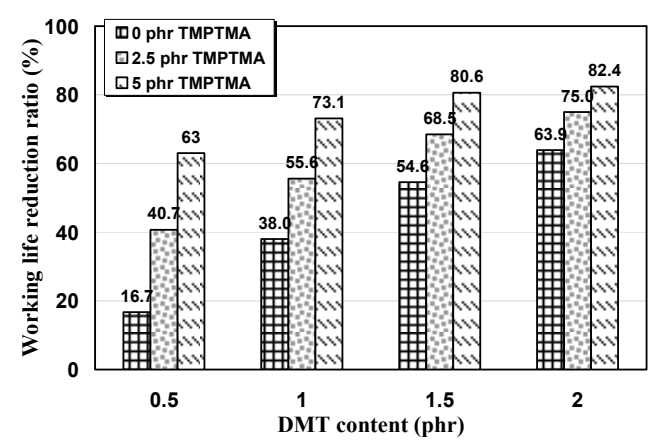

(b)

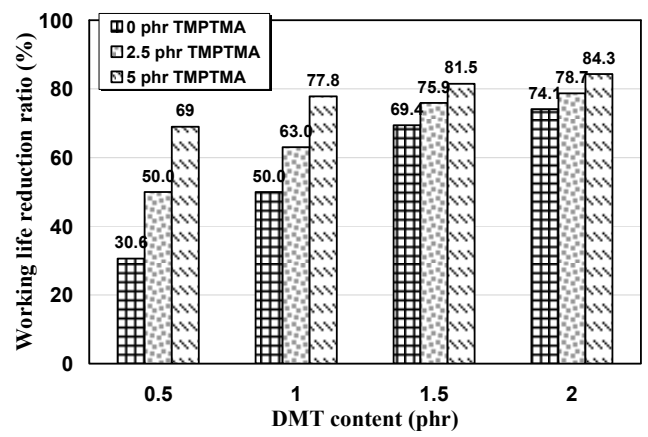

(c)

Figure 5. Effects of DMT and TMPTMA contents on the working life reduction ratio of acrylic polymer concrete cured at different temperatures. (a) $-20{ }^{\circ} \mathrm{C}$; (b) $-10{ }^{\circ} \mathrm{C}$; and (c) $0{ }^{\circ} \mathrm{C}$. 
The results presented in this study were in agreement with those of previous research studies. Fowler et al. [16] observed that the working life of $60 \mathrm{~min}$ was achieved by adding 3\% initiator and $1.5 \%$ promoter to MMA PC at $-1{ }^{\circ} \mathrm{C}$. Kobayashi et al. [10] reported that the working life of $140 \mathrm{~min}$ was be obtained using 1\% promoter and 5\% TMPTMA. According to Haddad et al. [9], the working life of 70 min was obtained by adding $2.5 \%$ initiator and $1.5 \%$ promoter at $-1{ }^{\circ} \mathrm{C}$, while that of $47 \mathrm{~min}$ were obtained by adding $4 \%$ initiator and $2 \%$ accelerator at the same temperature conditions. All these previous findings confirm that the working life of PC substantially depends on the contents of promoter and cross-linking agent, as well as the curing temperature.

From the results of this study, it is important to note that the required working life of acrylic PC could be successfully achieved even at curing temperatures as low as $-20-0{ }^{\circ} \mathrm{C}$ solely by controlling the contents of promoter and cross-linking agent.

\subsection{Relationship between Setting Time of Binder and Working Life of Acrylic PC}

While the correlation between setting time of binder and working life of PC at room temperature is well documented, little information is currently available on their relationship at sub-zero temperature conditions. In order to identify the relationship, a regression analysis was conducted using the experimental data sets obtained from this study as shown in Figure 6. The results show that the best fit was obtained when the data points were fitted to a linear function of $t_{\mathrm{w}}=1.0757 t_{\mathrm{s}}+4.0032$; where $t_{\mathrm{w}}$ is the working life of acrylic PC (min) and $t_{\mathrm{s}}$ is the setting time of binder (min). The correlation coefficient was found to be $R^{2}=0.9496$, indicating that the derived equation is statistically quite significant. Accordingly, the developed equation would be potentially used for estimation of acrylic PC's working life once the binder's setting time is given.

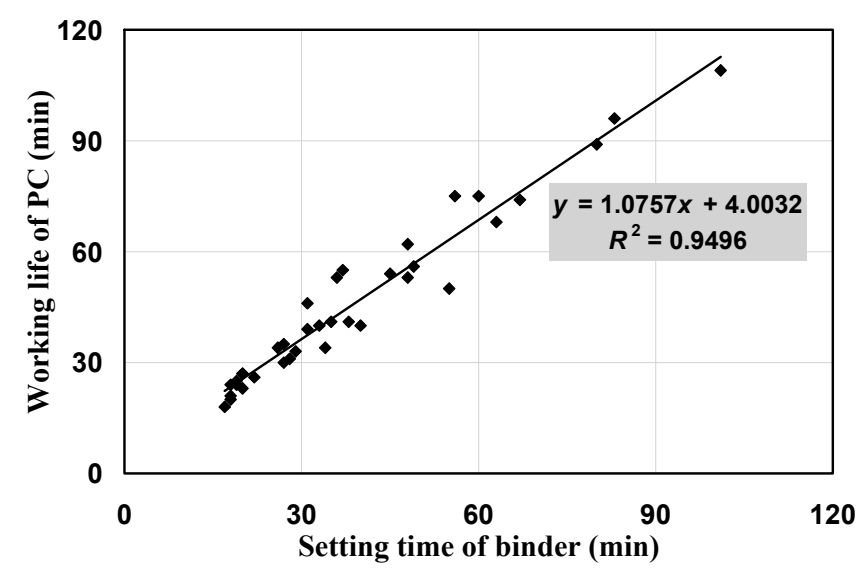

Figure 6. Relation between binder's setting time and acrylic polymer concrete's working life at sub-zero temperatures.

\subsection{Statistical Analysis of DMT and TMPTMA Effects}

A two-way analysis of variance (ANOVA) was carried out to determine the effects of DMT and TMPTMA on the working life of acrylic PC as shown in Tables 3-5. The results show that the F-ratios of DMT evaluated at all curing temperatures were higher than the F-critical value of 4.757. In addition, the $p$-values evaluated for each curing temperature were found to be lower than the significance level of 0.05 . 
These findings confirm that DMT had a statistically meaningful contribution in reducing the working life of acrylic PC. On the other hand, it is observed from Tables 3-5 that the F-ratios of TMPTMA evaluated at all curing temperatures were greater than the F-critical value of 5.143 while the $p$-values at all curing temperatures were smaller than the significance level of 0.05 . The results demonstrate that TMPTMA also had a statistical significance to the working reduction.

It is concluded, however, that TMPTMA had a greater impact on the working life reduction than DMT as the F-ratios of TMPTMA (i.e., 10.986-54.875) exhibited a larger variation than those of DMT (i.e., 11.554-22.710).

Table 3. Two-way ANOVA for working life of acrylic polymer concrete cured at $0{ }^{\circ} \mathrm{C}$.

\begin{tabular}{ccccccc}
\hline Variables & Sum of squares & Degree of freedom & Root mean square & F-ratio & $\boldsymbol{p}$-Value & F-critical value \\
\hline DMT & $1,780.3$ & 3 & 593.444 & 11.5543 & 0.00662 & 4.7570 \\
TMPTMA & $1,128.5$ & 2 & 564.250 & 10.9859 & 0.00986 & 5.1432 \\
Residual & 308.1 & 6 & 51.361 & - & - & - \\
Total & $3,216.9$ & 11 & - & - & - & - \\
\hline
\end{tabular}

Table 4. Two-way ANOVA for working life of acrylic polymer concrete cured at $-10{ }^{\circ} \mathrm{C}$.

\begin{tabular}{ccccccc}
\hline Variables & Sum of squares & Degree of freedom & Root mean square & F-ratio & $\boldsymbol{p}$-Value & F-critical value \\
\hline DMT & $2,326.9$ & 3 & 775.638 & 18.3703 & 0.00199 & 4.7570 \\
TMPTMA & $2,314.6$ & 2 & $1,157.333$ & 27.4105 & 0.00096 & 5.1432 \\
Residual & 253.3 & 6 & 42.222 & - & - & - \\
Total & $4,894.8$ & 11 & - & - & - & - \\
\hline
\end{tabular}

Table 5. Two-way ANOVA for working life of acrylic polymer concrete cured at $-20{ }^{\circ} \mathrm{C}$.

\begin{tabular}{ccccccc}
\hline Variables & Sum of squares & Degree of freedom & Root mean square & F-ratio & $\boldsymbol{p}$-Value & F-critical value \\
\hline DMT & $3,141.5$ & 3 & $1,047.194$ & 22.7102 & 0.00124 & 4.7570 \\
TMPTMA & $5,060.6$ & 2 & $2,530.333$ & 54.8749 & 0.00139 & 5.1432 \\
Residual & 276.6 & 6 & 46.111 & - & - & - \\
Total & $8,478.7$ & 11 & - & - & - & - \\
\hline
\end{tabular}

\section{Conclusions}

The research described in this paper addressed the development of mixture proportions for acrylic polymer concrete (PC) that can achieve the required working life even in low temperature conditions. To achieve this aim, the effects of curing temperature, promoter, and cross-linking agent on the working life of acrylic PC were identified based on a series of laboratory tests. On the basis of the findings of this study, the following conclusions can be made:

(1). The higher the curing temperature, the shorter the working life of acrylic PC, because the molecular motions of polymers increase with increased thermal energy supply to the system. The 
maximum working life tended to decrease from 108 to 75 as the curing temperature increased from -20 to $0{ }^{\circ} \mathrm{C}$.

(2). The working life of acrylic PC tended to decrease with increased contents of $N, N$-Dimethyl- $p$ toluidine (DMT) promoter and trimethylolpropane trimethacrylate (TMPTMA) cross-linking agent. However, no more than 2 phr DMT and 5 phr TMPTMA are recommended as the working life becomes hardly sensitive to the contents of additives beyond that point.

(3). The reduction ratio of working life tended to decrease as the curing temperature decreased and the contents of DMT and TMPTMA increased.

(4). This study successfully developed the mixture proportions for acrylic PC that can achieve the desired working life even in sub-zero temperature conditions.

(5). A linear function of reliably fitted the relationship between the working life of acrylic PC and the setting time of binder, which would be effectively used for prediction of acrylic PC's working life based on binder's setting time.

(6). A two-way analysis of variance (ANOVA) demonstrated that both DMT and TMPTMA affected the working life of acrylic PC; but TMPTMA had a slightly greater impact than DMT.

\section{Acknowledgments}

This research was supported by Basic Science Research Program through the National Research Foundation of Korea (NRF) funded by the Ministry of Education, Science and Technology (NRF-2012-0002161). This research was also supported by the Gachon University research fund of 2014 (GCU-2014-0109).

\section{Author Contributions}

Kyu-Seok Yeon managed the project as a principal investigator and drafted the manuscript. Jin-Yun Cha performed the experiment and data analysis; Jung Heum Yeon prepared the final manuscript and contributed to the experimental design, results discussion and conclusions.

\section{Conflicts of Interest}

The authors declare no conflict of interest.

\section{References}

1. Chandra, S.; Ohama, Y. Polymers in Concrete; CRC Press Inc.: Boca Raton, FL, USA, 1994; p. 163.

2. Chmielewska, B.; Czarnecki, L.; Sustersic, J.; Zaic, A. The influence of silane coupling agents on the polymer mortar. Cement Concr. Compos. 2006, 28, 803-810. [CrossRef]

3. Czarnecki, L.; Garbacz, A.; Kurach, J. On the characterization of polymer concrete fracture surface. Cement Concr. Compos. 2001, 23, 399-409. [CrossRef]

4. Shokrieh, M.M.; Heidari-Rarani, M.; Shakoyri, M.; Kashizadeh, E. Effects of thermal cycles on mechanical properties of an optimized polymer concrete. Constr. Build. Mater. 2011, 25, 3540-3549. [CrossRef] 
5. Solovjov, G.K.; Trambovetsky, V.; Kruger, D. Furan resin polymer concrete in the commonwealth of independent states (CIS). ACI Mater. J. 1994, 91, 158-160.

6. Kulshreshtha, A.K.; Vasile, C. Handbook of Polymer Blends and Composites; Rapra Technology Ltd.: Shrewsbury, UK, 2003; Volume 1, p. 674.

7. Mehta, P.K.; Monteiro, P.J.M. Concrete: Microstructure, Properties and Materials, 3rd ed.; McGraw-Hill: New York, NY, USA, 2006; p. 659.

8. Ohama, Y.; Kobayashi, T. Working life of polymethly methacrylate concrete and its control. J. Soc. Mater. Sci. Jpn 1979, 32, 215-221. [CrossRef]

9. Haddad, M.U.; Fowler, D.W.; Paul, D.R. Factors affecting the curing and strength of polymer concrete. ACI J. 1983, 80, 396-402.

10. Kobayashi, T.; Ohama, Y. Low-temperature curing of polymethyl methacrylate polymer concrete. Transp. Res. Rec. 1984, 1003, 15-18.

11. ASTM International. ASTM C33. Standard Specification for Concrete Aggregates; ASTM International: West Conshohocken, PA, USA, 2003.

12. Japanese Industrial Standard (JIS). JIS R 5201. Physical Testing Methods for Cement; JIS: Tokyo, Japan, 1997.

13. Ohama, Y. Determination methods for working life of polyester resin concrete. Am. Concr. Inst. 1978, 58, 31-40.

14. ASTM International. ASTM D2471-99. Standard Test Method for Gel Time and Peak Exothermic Temperature of Reacting Thermosetting Resins (Withdrawn 2008); ASTM International: West Conshohocken, PA, USA, 1999.

15. Hyun, S.H.; Yeon, J.H. Strength development characteristics of UP-MMA based polymer concrete. Constr. Build. Mater. 2012, 37, 387-397. [CrossRef]

16. Fowler, D.W.; Meyer, A.H.; Paul, D.R. Low temperature curing of polymer concrete. In Proceedings of the 3rd ICPIC, Koriyama, Japan, 1981; pp. 421-434.

(C) 2015 by the authors; licensee MDPI, Basel, Switzerland. This article is an open access article distributed under the terms and conditions of the Creative Commons Attribution license (http://creativecommons.org/licenses/by/4.0/). 